\title{
Computer-Aided Weaving: From Numerical Data to Generative Textiles
}

\author{
Marinos Koutsomichalis \\ Candidate PhD \\ De Montfort University \\ P.O. Box 1901 E. Antistaseos \\ 71004 Heraklion, Greece \\ me@marinoskoutsomichalis.com
}

\author{
Afroditi Psarra \\ PhD, Complutense \\ University of Madrid \\ 17, El. Venizelou \\ 15561 Athens, Greece \\ stereochic@gmail.com
}

\section{INTRODUCTION}

Contemporary computers are direct descendants of the Jackard's loom - an industrial era machine that used punched cards as a way of calculating and representing numerical data to be subsequently transformed into weaving patterns (Essinger 2004) - and of Babbage's Analytical Engine, which employed a variation of the same system to perform complex probabilistic calculations (Swade 1991). In that vein, Ada Lovelace foresaw the future application of programming as the means to realise computer-generated music and graphics (Charman-Anderson, 2013) and this way prepared the grounds for the entire informational revolution to follow. Weaving is to be understood as a constitutionally algorithmic process, which has henceforth evolved in parallel to computer technology. In that vein, contemporary fabrication tactics, such as those suggested by Hatch (2013), constitute a platform for the further development of new technologies and/or for the re-appropriation of existent ones. A re-conceptualisation of the design process through data visualisation and parametric design schemata is cast possible this way (Romano \& Cangiano 2014, pp. 170-172).

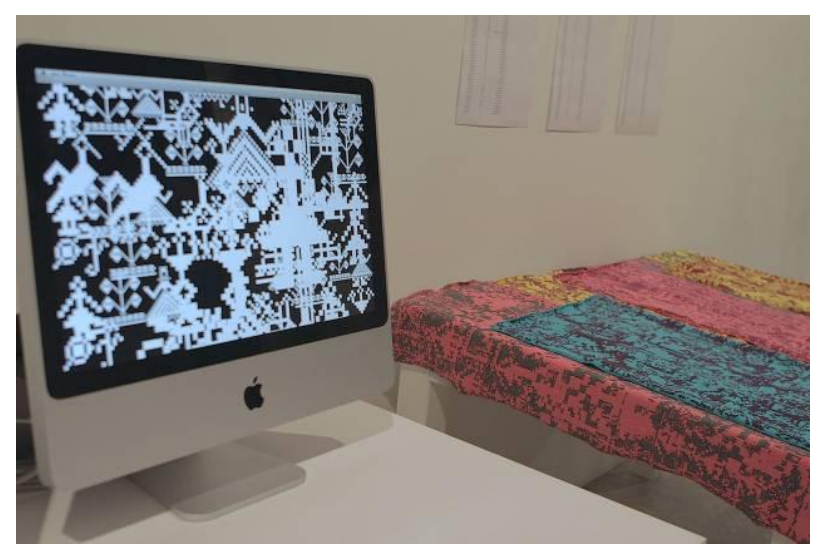

Figure 1: Detail from the Oiko-nomic Threads Installation

\section{ALGORITHMIC APPROACHES TO WEAVING}

That said, there have been several notable projects which all account for an explicitly algorithmic approach to textile-based art. Drawing on the emblematic work of the Bauhaus Weaving Workshop (Smith 2014), or on the patchwork assemblages of Lucas Samaras' Reconstruction series, several artists have attempted to redefine weaving/knitting technologies to account for a series of new fabrication methodologies based on more or less sophisticated algorithmic models. Consider for example, Ele Carpenter and The Open Source Embroidery Collective's Html Patchwork/Patchwiki - a collectively stitched quilt of 216 web-safe colours and their six figure hexadecimal identification codes - or Santoro's Sonic Fabric - an audio-enabled textile woven with magnetic tapes. Farina's Augmented Weaving Machine and Canet/Guljajeva's Knittic are two instances of projects that employ D.I.Y./hacked equipment to implement computer-aided weaving; in both cases it is cast possible to knit digital images at will. Another interesting case is that of $\mathrm{Di}$ Gilpin's Codes: Hidden secrets of knitting, where the algorithms used by Bletchley Park's female code-breakers are translated into woven patterns.

\section{FROM FINANCIAL DATA TO GENERATIVE TEXTILES}

Under these premises and in the context of the Oiko-nomic Threads installation project, the production of a generative textile has been attempted (Koutsomichalis et al. 2014) - see Figure 1. The project may be understood as a symbiotic hybrid where different incarnation of the very same technology and of their derivative labour paradigms meet and are, accordingly, interrogated; this way it is attempted to zero in the fundamentals of economy as manifested throughout the last centuries. 


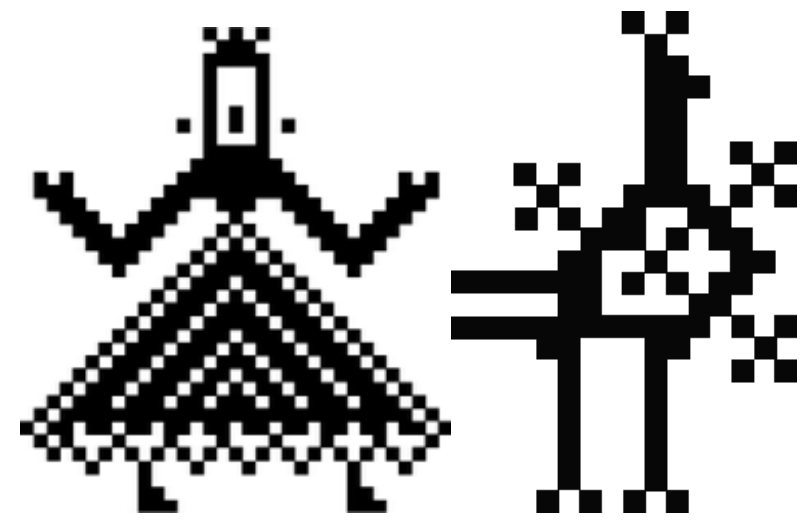

Figure 2: Examples of digitised folk motifs

Technically, the installation resolves around the fabrication of a generative textile in real-time; a task conducted both by means of algorithmic computer instructions as well as via human interaction. The decoration of the fabric has been conceived as a machine-intended interpretation of a numerical database - representing the financial activities of the Greek National Manpower Employment Organisation - through another - a series of digitised folk patterns typically used as decorations in woven textiles, see e.g. Figure 2. On a conceptual level, these two datasets connote different kinds of economical models - domestic-based economy versus capitalism. The decoration is, then, the to be realised by means of sophisticated software (coded in $\mathrm{C}++)$ and with the aid of custom hardware designed specifically for the project. Note that the decoration is also bound to be affected by various glitches congenital to the hardware itself or due to inaccuracies on the operator's behalf - this is totally desired and in accordance with the project's thematic axis; it may be understood as a way to foreground particular qualities of the technology in use.

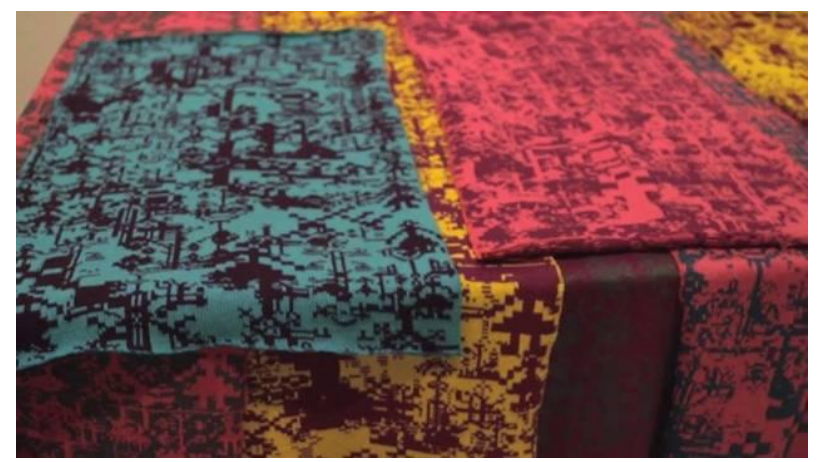

Figure 3: Algorithmically generated textiles

To generate the decoration, the software retrieves the first numerical entry from the dataset and maps its digits to a series of motifs using an one-to-one scheme. Their dimensions are then stochastically scaled, so that the sum of their widths is exactly 160 pixels but their individual widths are arbitrary and not equal with each other. Subsequently, they are transformed in matrixes, so that they are decomposed in discrete lines, and they are pushed in a sequential vector. On each iteration, the software composes a line by means of sequentially assembling the bottom lines of all available motifs, then it applies a simple affine transformation to compensate for the incompatibility between computer pixels and stitches (the latter are not square), and finally converts the result into a binary string of numbers to be sent over serial to the knitting machine. Once sent, the corresponding lines are then removed from each matrix. Whenever a motif is completed - that is whenever there are no more associated lines - a new entry is retrieved from the dataset and the entire process is repeated, only that this time the resulting motifs are to be interpolated with the remaining matrices in the vector and following simple Boolean operations. In this way, new kinds of patterns are generatively created. The entire process is then repeated for as long as the software is running; hence the resulting decoration has no explicit end. It has to be noted, finally, that the software also applies a simple affine transformation to the decoration so that it compensates for the incompatibility between pixels and stitches. As shown in Figure 3, the generated textiles are contingent and ever-permuting.

\section{REFERENCES}

Charman-Anderson, S. (2013) Ada Lovelace: Victorian computing visionary. In CharmanAnderson, S. (ed.), A Passion For Science: Tales of Discovery and Invention. Findingada.com.

Essinger, J. (2004) Jacquard's Web: How a handloom led to the birth of the information age. Oxford University Press, New York.

Hatch, M. (2014) The Maker Movement Manifesto: Rules for Innovation in the New World of Crafters, Hackers, and Tinkerers. McGraw-Hill, Chicago.

Koutsomichalis, M., Varela, M., \& Psarra, A. (2014) Oiko-nomic threads. ACM International Symposium on Wearable Computers, Seattle, WA, September 13-17, 2014, pp 59-64. ACM, New York.

Swade, D. (1991) Charles Babbage and his Calculating Engines. Science Museum, London, UK.

Romano, Z. \& Cangiano, S. (2014) Open Sourcing Wearables. In Bihanic, D. (Eds) Empowering Users through Design: Interdisciplinary Studies and Combined Approaches for Technological Products and Services (pp. 153-176). Springer, New York.

Smith, T. (2014) Bauhaus weaving theory: From feminine craft to mode of design. University of Minnesota Press, Minneapolis, USA. 